\title{
Regional Integration and Economic Growth: A Convergence Analysis for Pakistan
}

\section{Zeeshan Siddiqui* and Rummana Zaheer}

Department of Economics, University of Karachi, Main University Road, Karachi 75270, Pakistan

*Corresponding author: Zeeshan Siddiqui, Department of Economics, University of Karachi, Main University Road, Karachi 75270, Pakistan, Tel: +922199261300; Email: zseconomist@gmail.com

Rec date: June 06, 2017, Acc date: July 28, 2017, Pub date: August 4, 2017

Copyright: ( 2017 Siddiqui Z, et al. This is an open-access article distributed under the terms of the Creative Commons Attribution License, which permits unrestricted use, distribution, and reproduction in any medium, provided the original author and source are credited.

\section{Abstract}

The hasty economic progress of emerging economies has opened markets for their international trade during the last 20 years. Therefore, the significance of the topic has simulated a large theoretical and empirical literature of trade and its impact on growth. However, we are interested to find out the impact of regional integration on economic growth to analyze the convergence and specifically the convergence of per capita GDP. This article presents the empirical evidence that countries with open, large and more developed neighboring countries grow faster and converge more than the closed, smaller less developed neighboring economies. In this study, we have examined the issue of convergence for Pakistan during 1980-2016 employing cointegration technique of convergence. It is recommended to policy makers to focus on those factors which are cumulating growth in the country rather to increase the commodity prices.
\end{abstract}

Keywords: GDP; Trade; Commodity Prices; Economies; Finance; Product

\section{Introduction}

The quick financial development of creating nations that opened their business sectors to organized commerce amid the previous two decades has fortified an extensive experimental and hypothetical writing on the effect of exchange on development. This writing reasons that organized commerce and development are decidedly associated.

The concept of convergence is well known in the literature implying "forces accelerating the growth of nations who were latecomers to industrialization and economic development give rise to a tendency towards convergence of levels of per capita product or, alternatively of per worker product" [1]. David Hume fought that exchange of innovation to be a main impetus for meeting of poorer and wealthier nations by augmenting the extent of their business sectors. Theoretically, two expansive ideas of joining can be perceived, to be specific merging and contingent convergencel. The previous identifies with merging of per capita wage through the "getting up to speed prepare" while the last implies the union of cross-sectional scattering of per capita pay. Convergence (s) occurs if the dispersion (inequality) of per capita declines over time.

Financial specialists put unreasonable accentuation on the investigation of development process just to discover "this procedure is counterbalanced by new unsettling influences that tend to build scattering". In this way, it might be feebly expressed that $b$ joining possibly a fundamental, however, not an adequate condition for $\mathrm{s}$ convergence. All things considered, monetary development and wage disparity are created by mind boggling and bunch elements of which pay is just a single of them. Financial hypothesis proposes reasons why poor nations may "make up for lost time" with rich nations after some time regarding per capita pay. Specifically, the Solow-Swan neoclassical development display predicts that capital will spill out of rich to poorer. A third idea of joining to be specific restrictive b union is frequently discussed which considers the non-indistinguishable nature of unfaltering state development way for per capita yield for various countries, along these lines advancing speedier monetary development in the last mentioned. The key fundamental suspicion is that there are consistent losses to capital. This implies the returns to capital are higher in poor nations, which are generally inadequately supplied with capital, than in blessed by the goods capital rich economies. There is a developing empirical literature on merging and extensive outlines can be found [2-4]. For extensive specimens of nations that cut crosswise over districts and wage levels, a large portion of the confirmation neglects to bolster total union. Albeit extensive specimens of nations don't show meeting, the proof of joining is somewhat stronger for littler gatherings of nations exceptionally among nations at comparable pay levels. The exact proof of cointegration among the world's wealthiest and poor nations despite the fact that they neglect to do as such for medium wage nations [2,5] The hypothetical supports are given to join the club theory, as per which meeting will happen among subsets rather than wide examples of nations. The focal target of this review is to exactly analyze regardless of whether union is happening in Pakistan [3,4]. The nations of South Asia have shaped a local piece known as South Asian Association for Regional Cooperation (SAARC). SAARC includes seven nations: Bangladesh, Bhutan, Nepal, India, Maldives, Pakistan and Sri Lanka. Segment II plots the notable components of the expanded SAARC nations. Segment III manages the exact examination of the issue of meeting. Area IV contains a talk of the outcomes and Section $\mathrm{V}$ closes the significant discoveries of the review.

\section{SAARC: A Diversification for Regional Unity}

This section provides the brief review of the SAARC economies and will discuss the political, social and economic structure of the SAARC countries. The performance of the economies is discussed by its various Economic and Human Development Indicators. 
Page 2 of 3

The South Asian locale involving the SAARC nations is interesting. SAARC nations contrast gigantically in size, populace and monetary advancement. They likewise share unique social, monetary and political game plan. These divergences offer tremendous troubles and in addition challenges in the development of SAARC. Of the seven SAARC nations, every one of the nations excepting India and Pakistan are little in regional size. Two nations (Bhutan, Nepal) are land-bolted and their contact with whatever remains of the world for all intents and purposes relies on upon the collaboration of India, while Maldives and Sri Lanka are island states. India, by its sheer size, involves more than 70 for every penny of the landmass of the area and its regional and sea limit embraces all the SAARC nations. Then again, none of the six individuals have a typical limit with each other. Regarding populace figures, India has about 90 for every penny of the district's populace. India's predominance is not limited to measure as it were. India's GDP represents almost 77 for each penny of the area's GDP in 2000 (World Tables, 2002). As far as assembling quality included, India contributes about 80 for every penny of the district's assembling esteem included and furthermore overwhelms the fare and import volume of the area. As a result of her vast land range, India is likewise blessed by the gods with common assets and minerals and some of these (e.g., uranium, press mineral, gold and silver and so forth.) are select to India alone.

\section{Methodology}

\section{Data and estimation}

The data have been collected for Pakistan from the World Data Bank for the period 1980-2016. GDP per capita CPI govt. consumption, GDP and private consumption.

Time series investigations are for the most part based of stochastic methodologies like integration. In the event that the distinctions of times arrangement (or other liner blend) contains a unit root than we confront an outrageous sort of disparity. This section explains the convergence hypotheses and its empirical tests by employing panel data methodology. The concept of convergence can be defined in several ways. According to Quah [3] "there is conditional convergence if poor economies tend to grow faster than rich ones, and a group of economies are converging in the sense if dispersion of their real per capita GDP levels tends to decrease over time. "Romer [6] concisely refers to three critical explanations behind the meeting procedure. To begin with, the neo-established development models foresee nations join to their adjusted development ways. Hence, to the degree that distinctions in yield per laborer emerge from nations being at various focuses in respect to their adjusted development ways, one would anticipate that the poorer nations will make up for lost time to the wealthier. Second, the Solow show infers that the arrival on capital is lower in nations with more capital per laborer. Accordingly, capital spill out of rich to poor nations will eventuate prompting merging. In conclusion, if there are slacks in the dissemination of learning, pay contrasts can emerge since a few nations are yet to utilize the fitting procedure of creation. These distinctions can vanish once poorer nations access the front-line innovation. Give yit a chance to be the characteristic logarithm of per capita GDP for economy $i(i=1,2, \ldots N)$ amid period $t$ and st be the standard deviation of yit crosswise over I at time t. Total (s) joining can be tried by assessing the accompanying model:

$\mathrm{st}=\mathrm{a}+\mathrm{bt}+\mathrm{nt}$ where, an and b are parameters and nt is the stochastic mistake term. A noteworthy negative an incentive for $b$ suggests total meeting, while $b^{3} 0$ infers non-convergence.

b-joining can be tried by running the accompanying relapse of development of per capita GDP crosswise over economies:

$$
\text { (yit-yi,t-T)=a+byi,t-T+nt. }
$$

Where $t$ shows the finish of the time interim and $(\mathrm{t}-\mathrm{T})$ is the starting (beginning) of the time interim and $\mathrm{nt}$ is the stochastic blunder term. As far as condition (2) a critical negative an incentive for $b$ infers beta (b) joining, while $\mathrm{b}^{3} 0$ infers no union. The idea of contingent beta meeting (bc) can be inferred by enlarging condition (2) by including an arrangement of control factors xi (e.g., venture, sparing, populace, openness and so on.) that are required to decide the enduring state development of per capita yield. Along these lines, restrictive beta union $(\mathrm{bc})$ can be tried by estimating the following model:

(yit-yi,t-T) $=$ a + byi,t-T+gxi+nt.

In terms of equation (3) a significant negative b implies convergence holds conditionally.

\section{Results and Discussion}

\begin{tabular}{|c|c|c|c|c|}
\hline \multicolumn{5}{|c|}{ Trend assumption: Linear deterministic trend } \\
\hline \multicolumn{5}{|c|}{ Series: CPI GCON GDP PCON } \\
\hline \multicolumn{5}{|c|}{ Lags interval (in first differences): 1 to 2} \\
\hline \multicolumn{5}{|c|}{ Unrestricted Cointegration Rank Test (Trace) } \\
\hline Hypothesized & & Trace & 0.05 & \\
\hline No. of $\mathrm{CE}(\mathrm{s})$ & Eigenvalue & Statistic & Critical Value & Prob.** \\
\hline None * & 0.418678 & 59.89556 & 47.85613 & 0.0025 \\
\hline At most 1 * & 0.360976 & 39.28246 & 29.79707 & 0.0030 \\
\hline At most 2 * & 0.329280 & 22.26553 & 15.49471 & 0.0041 \\
\hline At most 3 * & 0.170168 & 7.088223 & 3.841466 & 0.0078 \\
\hline \multicolumn{5}{|c|}{ Trace test indicates 4 cointegrating eqn(s) at the 0.05 level } \\
\hline \multicolumn{5}{|c|}{ * denotes rejection of the hypothesis at the 0.05 level } \\
\hline \multicolumn{5}{|c|}{${ }^{* *}$ MacKinnon-Haug-Michelis (1999) p-values } \\
\hline \multicolumn{5}{|c|}{ Unrestricted Cointegration Rank Test (Maximum Eigenvalue) } \\
\hline Hypothesized & & Max-Eigen & 0.05 & \\
\hline No. of $\mathrm{CE}(\mathrm{s})$ & Eigenvalue & Statistic & Critical Value & Prob.** \\
\hline None & 0.418678 & 20.61311 & 27.58434 & 0.3003 \\
\hline At most 1 & 0.360976 & 17.01693 & 21.13162 & 0.1712 \\
\hline At most 2 * & 0.329280 & 15.17731 & 14.26460 & 0.0358 \\
\hline At most 3 * & 0.170168 & 7.088223 & 3.841466 & 0.0078 \\
\hline \multicolumn{5}{|c|}{ Max-eigenvalue test indicates no cointegration at the 0.05 level } \\
\hline${ }^{*}$ denotes reje & f the hypo & the 0.05 & & \\
\hline
\end{tabular}




** MacKinnon-Haug-Michelis (1999) p-values
\begin{tabular}{|l|l|l|l|l|}
\hline Normalized cointegrating coefficients (standard error in parentheses) \\
\hline GDP & Gvt. Con & CPI & Pvt. Con & \\
\hline & -1.8301 & 1.959935 & -1.279 & \\
\hline & $(0.62482)$ & $(0.80861)$ & $(0.29882)$ & \\
\hline
\end{tabular}

Table 1: This section elaborates the regression results.

We have used co integration technique for the convergence analysis. We have selected Pakistan to analyze its convergence in the SAARC countries and tried to present a clear picture.

From the above results, we have come to know that Pakistan's GDP has convergence tendency. In other words, all the variables in the model have long run association among them. From the long run equation, it can be seen clearly that government consumption and private consumption both have positive relation with GDP growth while CPI exerts negative impact on GDP growth (Table 1).

\section{Sources of Non-Convergence of GDP in SAARC Economies}

Meeting of per capita GDP remains a polemical issue in development financial aspects and there is no unambiguous view on the elements that prompt merging of yield crosswise over nations. It is hypothesized that merging of per capita yield comes about because of a blend of monetary and non-financial components. Diagnostically, there are two wide methodological perspectives that can clarify the union procedure crosswise over economies. The first being the mechanical "making up for lost time" theory where specialized knowhow spreads from the innovatively propelled nations to the innovatively in reverse nations bringing on joining in per capita yield levels. Openness in exchange, by expelling tax and non-tax hindrances, is thought to be the main thrust in quickening the reception and dissemination of suitable innovation crosswise over nations.

This view is very prevailing in the works of the traditional financial analysts like Adam Smith, David Ricardo, David Hume and even Alfred Marshal. In the current period, this view has additionally been subscribed and the rundown is not comprehensive $[1,7-10]$.

The second view is gotten from the transitional progression of the neoclassical development models. Neoclassical development models foresee that if nations have distinctive capital-work proportions, their development ways will in the long run join to a consistent state development way on account of unavoidable losses to capital. Indeed, even in an expanded Solow display, can indicate joining in spite of the fact that at a much slower rate [11].

\section{Conclusion}

The economy of Pakistan is the 25th greatest on the planet to the extent acquiring power equity (PPP), and 43th greatest to the extent apparent GDP. Pakistan has a mass of more than 190 million (the world's 6th greatest), giving it an apparent GDP for each capita of $\$ 1,429$, which positions 140 th on the planet. In any case, Pakistan's undocumented economy is surveyed to be $36 \%$ of its general economy, which is not thought about while figuring per capita pay [12]. Pakistan is a making country and is one of the Next Eleven, the eleven countries that, close by the BRICS, can twist up doubtlessly one of the world's colossal economies in the 21st century. Regardless, after a long time of war and social shakiness, beginning at 2013, bona fide insufficiencies in basic organizations, for instance, railroad transportation and electric power period had made. The economy is semi-industrialized, with centers of improvement along the Indus River. In this particular research, we have analyzed the factors like government and private consumption and CPI in the context of GDP growth of the country. We have captured the long run equilibrium relation between the variables of the model. It has also been found that private and government consumption both positively impact GDP growth of Pakistan.

On the behalf of above results it is recommended to policy makers to focus on those factors which are cumulating growth in the country rather to increase the commodity prices.

\section{References}

1. Baumol WJ (1986) Productivity Growth, Convergence and Welfare: What the Long- Run Data Show? American Economic Association 76: 1072-1085.

2. Ben DD (1998) Convergence Clubs and Subsistence Economies. Journal of Development Economics 55: 153-169.

3. Quah D (1997) Empirics for Growth and Distribution: Stratification, Polarization, and Convergence Clubs. Journal of Economic Growth 2: 27-59.

4. Quah D (1995) Empirics for Economic Growth and Convergence. European Economic Review 40: 1353-1375

5. Chatterji M (1992) Convergence Clubs and Endogenous Growth. Oxford Economic Review Policy 8: 57-69.

6. Romer PM (1986) Increasing Returns and Long-Run Growth. Journal of Political Economy 94: 1002-1037.

7. Abramovitz M (1986) Catching Up, Forging Ahead and Falling Behind. Journal of Economic History 46: 385-406.

8. Abramovitz M (1990) The Catch-Up Factor in Postwar Economic Growth. Economic Inquiry 28: 1-18.

9. Maddison A (1987) Growth and Slowdown in Advanced Capitalist Economies: Techniques of Quantitative Assessment. Journal of Economic Literature 25: 649-698.

10. Maddison A (1991) Dynamic Forces in Capitalist Development: A Long Run Comparative View. Oxford University Press.

11. Mankiw NG, D Romer, DN Weil (1992) A Contribution to the Empirics of Economic Growth. The Quarterly Journal of Economics 107: 407-437.

12. Zaheer R, Zeb A (2015) Economic Integration of Eastern Countries with European Union and United States - 1990-2012. Euro-Asian Journal of Economics and Finance 3: 90-102. 